\title{
Freud y la clínica del síntoma
}

\section{Freud and the clinic of the symptom}

\author{
Roberto Bertholet
}

\section{RESUMEN}

El presente escrito resulta de la desgrabación y edición de la clase Teórica de la cátedra "Psicoanálisis II", de la Facultad de Psicología de la Universidad Nacional de Rosario, que he dictado en la apertura del año académico 2019. En la misma, he destacado la doble dimensión de todo síntoma: ser un mensaje cifrado, inconsciente, que requiere una interpretación adecuada que reintegre su verdadero sentido, al mismo tiempo que una satisfacción pulsional sustitutiva que se repite, luego de haber quedado fijado una satisfacción y un modo de defensa que termina resultando anacrónico y, por lo tanto, inútil.

Para dar cuenta de esa dimensión pulsional del síntoma, que de ningún modo desconoce o reduce la importancia del síntoma como verdad inconsciente, se hace necesario recurrir a los textos freudianos de 1920 en adelante, a partir de su elaboración sobre la pulsión de muerte, la segunda tópica, el superyó, la necesidad de castigo y el masoquismo moral y femenino. Así, los textos "Inhibición, síntoma y angustia" y "Análisis terminable e interminable" son los que brindan una perspectiva freudiana precisa respecto de

\section{AbSTRACT}

This writing is the result of the desgrabación and edition of the theoretical class of the chair "Psychoanalysis II", of the Faculty of Psychology of the National University of Rosario, that I have dictated in the opening of the academic year 2019. In the same, I have highlighted the double dimension of any symptom: to be an encrypted, unconscious message, which requires an adequate interpretation that reintegrates its true meaning, at the same time as a substitute drive satisfaction that is repeated, after having been fixed a satisfaction and a way of defense that ends resulting anachronistic and, therefore, useless.

To account for this drive dimension of the symptom, which in no way ignores or reduces the importance of the symptom as unconscious truth, it is necessary to resort to the Freudian texts from 1920 onwards, from its elaboration on the death drive, the second topic, the superego, the need for punishment and moral and feminine masochism. Thus, the texts "Inhibition, symptom and anguish" and "Terminable and endless analysis" are those that provide a precise Freudian perspective regarding a clinical symptom that illuminates 
una clínica del síntoma que ilumina "el "the hyperpower of the quantitative fachiperpoder del factor cuantitativo" en las tor" in neuroses.

neurosis.

Palabras Clave:

Síntoma - Pulsión - Fijación - Angustia Tánatos

\section{KeYWORDS}

Symptom - Drive - Fixation - Anguish Tanatos 


\section{Perspectiva}

En 1937, Sigmund Freud -teniendo 80 años de edad y con 50 años de práctica y de elaboración clínica- nos deja un texto, "Análisis terminable e interminable", que podemos usar a fin de trazar una perspectiva interesante para la enseñanza universitaria del Psicoanálisis.

En "Análisis terminable e interminable", Freud destaca cuatro factores que inciden con notable fuerza en el trabajo analítico, considerándolos "desfavorables para el efecto del análisis" (Freud, 1937, p. 223). Ellos son:

a) el influjo de traumas (Freud, 1937, p. 223 y 227)

b) la intensidad de las pulsiones

(Freud, 1937, p. 223 y 224; p. 227 y 228 )

c) "la alteración perjudicial del yo, adquirida en la lucha defensiva, en el sentido de un desquicio y una limitación" (Freud, 1937, p. 223);

d) la desautorización de la feminidad; para la mujer, la envidia del pene y para el hombre, la revuelta contra su actitud pasiva o femenina hacia otro hombre (Freud, 1937, p.252), explicado por Freud en función de la lógica Edipo/falo/castración.

Nos ocuparemos de lo relacionado con la intensidad de las pulsiones, en particular desde la perspectiva del síntoma y la repetición.

Antes de destacar ese ángulo en particular, es conveniente hacer un recorrido por las primeras conceptualizaciones sobre el síntoma, como mensaje inconsciente, censurado y deformado, que, justamente, de ese modo, quiere decir algo.

\section{SíNTOMA Y SENTIDO INCONSCIENTE}

Sigmund Freud abrió su consultorio, en Pascuas de 1886, ofreciendo tratamiento al malestar de los "enfermos nerviosos" que lo consultaban pidiendo alivio, luego de diferentes terapias, infructuosas, algunas de las cuales el mismo Freud llegó a practicar. Su modo de escucha y su invitación a la palabra provocó un enorme paso respecto de las prácticas psiquiátricas de su momento, haciendo que el sin-sentido -que presentaba el malestar de cada uno de sus "pacientes", ese sinsentido que perturba el confort y el placer de la vida- deje su lugar al sentido que se descubre subyacente a ese malestar. Que lo llamara síntoma expresó, desde sus inicios, el espíritu freudiano de considerar que el sin-sentido es el indicio de un proceso desconocido, de una causa eficiente. Un enigma a ser descifrado. El psicoanalista, por la posición discursiva que toma y por la invitación que hace a quien lo consulta -directamente o por alusión-, promueve la creencia en el síntoma, la creencia en el sentido del síntoma. Y será la condición de posibilidad del trabajo de análisis, bajo transferencia.

En dirección contraria, la Asociación de Psiquiatría Americana ha tomado la decisión de eliminar, en los diagnósticos de su Manual Diagnóstico, DSM, el concepto de síntoma para convertir todo en trastorno, noción que pone el acento únicamente en lo disfuncional, que debe ser corregido lo antes posible.

Volviendo al Psicoanálisis, digamos que la propuesta de Freud, desde sus primeros escritos a fines del siglo XIX, fue atribuirle al síntoma y a su inicial sinsentido un sentido cifrado, inconsciente, 
a ser descifrado a medida que avanza la experiencia de un análisis.

Pero no sólo descubre el sentido inconsciente, sino que encuentra que el mismo se presentaba con una cualidad particular, asombrosa para el mismo Freud en 1890: su carácter sexual; con un agregado nada menor, que iba a ir tomando cada vez más relevancia en su descubrimiento y cada vez más lugar en su doctrina: el sentido sexual se anclaba en condiciones de la vida infantil. Será una perspectiva que nunca abandonará a lo largo de sus 50 años de elaboración epistémica.

Como consecuencia del deseo de Freud, el síntoma pasa de ser un sin-sentido que se repite dis-placenteramente, a ser algo que tiene todas las propiedades de un hecho de la realidad psíquica, altamente elaborado por el aparato psíquico: el síntoma tiene sentido y se articula con experiencias y significaciones, en relación con los acontecimientos más particulares del sujeto. A su vez, la vida infantil, la sexualidad infantil participa en lo más medular del proceso de formación de síntomas y es motivo de represión por lo inconciliable e inadmisible que resultan algunos deseos sexuales infantiles al conjunto de representaciones propias del yo y del Ideal, complejo de Edipo mediante.

De este modo, los síntomas indican un retorno de lo reprimido. La tarea del análisis, desde esta perspectiva, es una tarea de desciframiento.

En la histeria, Freud descubrió que el síntoma es un mensaje que se presta a ser leído. Síntoma que tiene una significación, un sinn (término alemán usado por Freud, cada vez que se refiere al sentido de los síntomas).
La sorpresa que sigue a este descubrimiento es que, al ser interpretado, al serle transmitido su sentido, el síntoma desaparece.

En aquellos tiempos, Freud podía constatar una homogeneidad entre el sentido del síntoma y la palabra del analista, la interpretación.

Los síntomas tenían sentido y eran dóciles a la interpretación, la que transmitía al paciente las claves de su inconsciente. Dichas claves se referían a traumas, angustias y acontecimientos de la infancia, que generaban -por efecto de las defensas puestas en juego ya desde los tiempos infantiles- las condiciones de posibilidad de los síntomas, en sus diferentes expresiones: neurosis, perversiones y psicosis. Desde la misma infancia se presentan síntomas y no dejan de formarse permanentemente en la vida de cada ser humano, lo sepa o no, quiera darse cuenta o, por el contrario, no tolere admitirlos y los necesite desconocer para evitar la angustia.

Evidentemente, el síntoma -al ser algo que, por definición, molesta y perturba- no resulta placentero para el yo. También resulta propio del síntoma su carácter repetitivo. A todo esto, el yo quiere resolver el síntoma, pero se termina reconociendo impotente en esa lucha. La mayoría de las veces no hace más que acomodar su funcionamiento al síntoma.

Entonces, tenemos cuatro características del síntoma:

a) es displacentero

b) se repite

c) el yo es impotente para resolverlo

d) termina modificándose para convivir con el síntoma. Incluso, hasta puede -la mayoría de las veces- extraer de esa convivencia con el síntoma, ciertos 
beneficios, la ganancia secundaria de la enfermedad.

Lo sorprendente, para el mismo Freud, fue que, en ese trabajo de desciframiento bajo transferencia, la interpretación analítica resultara tan eficiente que llegara a provocar la desaparición del síntoma.

\section{2.- SÍNTOMA Y SATISFACCIÓN PULSIONAL}

Así, durante un tiempo, quizás no mucho, si se considera que rápidamente Freud mismo tuvo que incluir en su edificio teórico un concepto fundamental para comprender la estructura y el funcionamiento del aparato psíquico: las pulsiones.

El dato más característico de las pulsiones es su drang, su empuje, la fuerza con que busca satisfacción. Pulsiones parciales, sexuales, que en su combinación íntima con el trabajo inconsciente, participan de la formación del síntoma. Así, todo síntoma será siempre consecuencia de la acción combinada de estas dos dimensiones: el inconsciente y las pulsiones. Todo síntoma expresa una realización de deseo inconsciente $y$, al mismo tiempo, una satisfacción pulsional, que implica siempre al cuerpo.

Las primeras referencias teóricas fundamentales de la enseñanza freudiana que presentan estas dos dimensiones son: por una parte "La interpretación de los sueños”, de 1900, donde Freud expone su primera doctrina del inconsciente; por otra parte, en 1905 presenta al mundo "Tres ensayos para una teoría sexual", con su primera teoría de las pulsiones -que modificará en 1914 y luego en 1920- y su primera teoría de la sexualidad infantil -que modificará en 1923 y en 1931-.
Decíamos que esa inicial eficiencia interpretativa no se mantuvo largo tiempo. Quizás fue por efecto de la insatisfacción propia de sus pacientes histéricas -insatisfacción que, al mismo tiempo se renueva sobre la propia existencia. También se aplica al Otro, al partenaire, para provocarlo como deseante-. O haya sido posiblemente por la wiederholungszwang -repetición compulsiva- de las neurosis obsesivas de sus pacientes, ya que el síntoma obsesivo se mostrará -tal como sigue ocurriendo en la actualidad-inercialmente repetitivo a lo largo del tiempo.

Entonces, dos escenarios nuevos se le presentan a Freud:

a) la interpretación no mantiene su potencia transformadora

b) el síntoma mantiene su repetición.

El síntoma requiere, de tal modo, de nuevos conceptos para ser comprendido en las facetas que va presentando al trabajo psicoanalítico. A lo largo de los años, Freud fue construyendo nuevos conceptos que le iban permitiendo precisar mejor lo que está en juego en la vida humana y, por supuesto, en toda experiencia de análisis: complejo de Edipo, narcisismo, Ideal del yo, angustia, castración, identificación, falo, pulsión de muerte, superyó, ligazónmadre pre-edípica y tantos más, que son claves epistémicas para ubicar con la mayor precisión los poderosos factores que crean y mantienen la miseria neurótica, para tratar de incidir sobre ellos.

Justamente, el deseo de incidir sobre lo que se repite encuentra una dimensión del síntoma que no es metafórica, que no es la de ser un mensaje ofrecido para su desciframiento. No es tan solo la dimensión del retorno de lo reprimido, 
de una dimensión simbólica que puede ser leída y nuevamente reinstalada en la diacronía de un texto que ya no necesita ser censurado, sino que el deseo de Freud encontró al síntoma en su dimensión más real, resistente al desciframiento y extraño a él. Jacques Lacan caracterizó a lo real, en una de sus varias definiciones, como "lo que vuelve siempre al mismo lugar" (Lacan, 1964. P, 57). El síntoma, en su repetición, aún luego del trabajo simbólico al que lo sometía Freud, le presentaba una dimensión opaca a la interpretación y al sentido.

La significación descifrable no da cuenta de todo lo referido al síntoma. Hay algo más que el deseo inconsciente, deseo que se manifiesta en la realización que procura el aparato psíquico en el síntoma. Está, también, la fuerza del drang de toda pulsión, que se expresa de la forma más siniestra en la pulsión de muerte, más allá del principio del placer, no tomando en cuenta, de ningún modo, el principio del placer, guardián de la vida.

A lo largo de 50 años de investigación, Freud creó diferentes series conceptuales para ir echando luz a la enorme complejidad de la vida anímica:

- autoerotismo / narcisismo / Edipo / latencia / pubertad / vida adulta

- angustia / pulsión de muerte-Eros / trauma / fijaciones / inconsciente / fantasías / síntoma.

El movimiento de la primera secuencia, que va del autoerotismo a la vida adulta, se explica en función de la operación de la castración, que provoca una doble transformación:

a) de lo pulsional -que encuentra satisfacción en las zonas erógenas del cuerpo- al deseo -que conlleva la dimensión del deseo del Otro-. Jacques Lacan, en este sentido, dirá que "el amor es lo que permite al goce condescender al deseo" (Lacan, 1962/1963. p, 195). La castración requiere que sea el Otro, por medio de la función paterna, que introduzca algo que, en cada momento de esa secuencia, permita pasar de la satisfacción autoerótica al deseo que requiere del campo del Otro;

b) también es la castración la que, por medio de la función paterna, promueve pasar de la endogamia a la exogamia, liberando al sujeto del sometimiento de las condiciones infantiles de vida.

Para explicar la segunda secuencia, Freud recurre a los conceptos de angustia, trauma, pulsión, fijación y defensa.

\section{3.- Síntoma y Fijación}

Comencemos por el concepto de fijación. A fin de dar cuenta de una fuerza muy activa en todo síntoma, una inscripción imborrable de un primer encuentro con el goce, con la satisfacción pulsional -un primer encuentro siempre traumático-, Freud hace comparecer un término muy nítido en su significación habitual, común, incluso en su uso en la economía, en la biología, en la mecánica: la fijación. En cualquier campo semántico, la fijación se refiere a algo que es inmóvil o que inmoviliza a un objeto, o que crea las condiciones para mantener estable y sujetado a ciertas variables un proceso que tiende a ser inestable.

La experiencia de un análisis constata la repetición del síntoma y la fuerte resistencia a abandonar las satisfacciones que el síntoma y ciertas posiciones infantiles en la vida le procuran al sujeto. Esto fue llamado por Freud "infantilismo": modos anacrónicos e inútiles mantenidos 
tenazmente en la vida adulta. Estos modos, en tiempos infantiles, habían resultado defensas eficaces frente a situaciones de angustia. La fijación indica el modo de inscripción de ciertas representaciones que persisten a lo largo del tiempo. Este concepto apareció primero en función de la teoría traumática: fijación al trauma. Luego, en la teoría libidinal, como fijación -en la vida adulta- a un modo de satisfacción de las pulsiones parciales y zonas erógenas de la sexualidad infantil.

En "Más allá del principio del placer", es la fijación al trauma lo que lo lleva a construir una novedad en cuanto a la repetición, ya no tan sólo considerada como repetición de un sentido inconsciente sino una compulsión de repetición, en función de una inercia libidinal y una intensa satisfacción pulsional.

A su vez, considera Freud que la fijación está en el origen del proceso represivo, en una articulación íntima con la represión originaria y es condición de toda regresión. Así se lo manifiesta a S. Ferenczi en una carta del 6 de diciembre de 1910: "Si descomponemos la represión en a) fijación; b) represión propiamente dicha; c) retorno, la proposición principal es: el retorno se produce en el lugar de la fijación (...) (Freud, Ferenczi, 1908/1911. P, 285).

Entonces, síntoma, retorno $\mathrm{y}$ fijación. Si el síntoma es un retorno de lo reprimido que se produce en el lugar de la fijación, tenemos una articulación entre la significación (inconsciente) y lo libidinal en juego. Esto está retomado por Jacques Lacan, quien combina la ficción del inconsciente con la fixierung (término alemán de "fijación"), creando el neologismo conceptual “fixión”. Toda ficción del inconsciente incluye en su médula misma una dimensión de fijación libidinal, de referencia a la satisfacción pulsional que se repite en el síntoma.

\section{4.- SÍNTOMA Y ANGUSTIA}

En "Más allá del principio del placer" (1920), capítulo V, destacó Freud la función e importancia de la barrera de protección anti-estímulos para el aparato psíquico. En "Inhibición, síntoma y angustia” (1926) retoma esta concepción y reformula la teorización sobre el trauma ubicándolo como la efracción provocada por lo inasimilable de la intensidad de estímulos, en particular los pulsionales, que romperían tal barrera, sin ser descargados ni ligados.

A partir de la condición de desamparo inicial -hilflosigkeit- de la vida humana, Freud diferencia un primer momento lógico que ubica como "el núcleo genuino de peligro", de un segundo momento, cuando se produce el desplazamiento por la pérdida de objeto.

En el primer momento está en juego la exigencia de la intensidad pulsional mientras que en el segundo momento -el momento de la pérdida de objeto- se refiere al Otro materno.

Leemos en Freud:

“Cuando el niño añora la percepción de la madre, es sólo porque ya sabe, por experiencia, que ella satisface sus necesidades sin dilación. Entonces, la situación que valora como peligro es la de la insatisfacción, el aumento de la tensión de necesidad, frente al cual es impotente. Opino que desde este punto de vista todo se ponen en orden: la perturbación económica por el incremento de las magnitudes 
de estímulo en espera de tramitación constituye el núcleo genuino de 'peligro'. Con la experiencia de que un objeto exterior, aprehensible por vía de percepción, puede poner término a la situación peligrosa que recuerda al nacimiento, el contenido del peligro se desplaza de la situación económica a su condición, la pérdida de objeto. La ausencia de la madre deviene ahora el peligro; el lactante da la señal de angustia tan pronto como se produce, aún antes que sobrevenga la situación económica temida”. (Freud, 1926. P, 130).

En “Angustia y vida pulsional” (1933), Freud llama factor traumático a un estado en que fracasan los empeños del principio del placer. Sólo la magnitud de la suma de excitación convierte a una impresión en factor traumático. Las primeras y originarias situaciones de peligro nacen directamente del encuentro con una exigencia libidinal hipertrófica, proveniente de factores traumáticos. $\mathrm{Y}$ considera, retomando lo despejado en 1926, un doble origen de la angustia: en un caso como consecuencia directa del factor traumático, y en otro caso como señal de que amenaza la repetición de un factor así.

De tal modo:

- primer momento: angustia sin contenido psíquico, perturbación económica traumática por el incremento de las magnitudes de estímulo en espera de tramitación, núcleo genuino del peligro;

- segundo momento: la angustia por la ausencia de la madre

- tercer momento: cuando aparece la angustia de castración, la pérdida del pene, objeto de la amenaza de castración (en el varón) o la pérdida del amor del padre (en la niña).

La castración le da al primer momento traumático y a la angustia un contenido psíquico y allí tenemos al Otro articulado, así, a la exigencia pulsional.

Freud separa a la angustia traumática de la angustia de castración. La angustia de castración conduce a la formación del fantasma. Resulta, así, la construcción de los modos de defensa y del fantasma inconsciente. Del mismo modo, Jacques Lacan diferenciará, en el Seminario 11, la intensidad pulsional del montaje pulsional articulado al fantasma.

\section{SíNTOMA, PULSIÓN DE MUERTE Y SUPERYÓ}

En “Más allá del principio del placer”, Sigmund Freud le dio su nombre al empuje más desconocido y extraño, al mismo tiempo que más íntimo, más propio, inevitable e inherente a la condición humana: la pulsión de muerte, diferenciándolo de la pulsión sexual, de la pulsión de vida, de Eros. Lo llama también Tánatos que, en la mitología griega, refería a la muerte sin necesidad de violencia, la muerte que llega sin que nadie la anticipe, una muerte más bien muda y efectiva.

El nuevo concepto de pulsión de muerte y sus consecuencias sobre toda la teoría psicoanalítica llevan a Freud a replantear las bases mismas de la clínica y reformular los resortes fundamentales de la práctica del Psicoanálisis.

En el siglo XXI, dadas las manifestaciones del profundo malestar que la subjetividad presenta en la civilización de nuestros días, necesitamos recuperar 
decididamente los textos y formulaciones de Sigmund Freud a partir de que introduce los conceptos de narcisismo y de pulsión de muerte en 1914 y en 1920, lo que da como consecuencia dos textos fundamentales -"El yo y el ello" e "Inhibición, síntoma y angustia"-, textos necesarios no sólo para pensar correctamente lo que el Psicoanálisis puede aportar como una lectura novedosa sobre la vida humana -que ningún otro campo aportó jamás en la historia- sino también para evaluar las posibilidades de que el practicante dedicado al Psicoanálisis aplicado -a la terapéutica- cuente con los esclarecimientos y recursos suficientes para el tratamiento adecuado de las presentaciones actuales del sufrimiento, tan resistentes al trabajo simbólico y tan deslizadas hacia la presentación actuada y a la mostración más que dispuestas a la palabra y a la elaboración significante.

Entonces, el texto "Inhibición, síntoma y angustia” expresa el interés de Freud en las satisfacciones pulsionales cuando no se prestan fácilmente a que se abandone una repetición compulsiva. Se refiere, entonces, a la inercia psíquica, al masoquismo en la neurosis, a la necesidad de castigo, a la viscosidad de la libido, a las neurosis de destino y cuando se vive a la cura psicoanalítica como un peligro.

Es muy conveniente destacar un concepto introducido por Freud en 1923, en "El yo y el ello": el nuevo concepto de superyó, que al mismo autor le costó mucho diferenciar del ideal del yo.

Es la enseñanza de Jacques Lacan quien nos va a permitir avanzar en esta diferenciación: el superyó está alimentado por pulsión de muerte, lo que no ocurre con el Ideal. Para hacer aparecer el concepto de superyó, en 1923, a Freud le fue necesario el contar con el concepto de pulsión de muerte, de 1920. Si hubiera sido un mero sinónimo de Ideal del yo (concepto creado por Freud en 1914), no hubiera tenido ninguna necesidad de clonar conceptos. Si le fue indispensable introducir un nuevo significante (superyó) es porque con el mismo iluminaba algo que había permanecido opaco, refractario a ser elucidado. Eso opaco es del orden de un objeto del campo pulsional, invocante, la "voz" que claramente va a aparecer en las alucinaciones auditivas de la psicosis y que, en las neurosis, opera de manera áfona: se hace escuchar aún cuando no se la oiga. Freud la situaba como la voz de la conciencia moral y Jacques Lacan la destacará a partir del Seminario 10 y particularmente, en el Seminario 16 "De un Otro al otro".

El superyó: feroz, insensato y obsceno. Así lo caracteriza Jacques Lacan, dando una idea de las consecuencias que tiene, frecuentemente, la voz superyoica. En "El yo y el ello", en el $3^{\circ}$ capítulo, se pregunta de dónde extrae el superyó ese sesgo duro y cruel que alimenta su imperativo categórico (Freud, 1923. P, 36). Notemos que a este último término, "imperativo categórico", Freud lo toma del filósofo I. Kant para quien hay obligaciones que no dejan opciones, que no admiten considerar ningún margen de opción, ninguna variable que permita elección ni alternativa más que la que ordena el imperativo. Para responder a esa pregunta, Freud necesita, en el capítulo siguiente, referirse a las dos clases de pulsiones, donde hace presentes a Eros y Tánatos y a los procesos de mezcla y desmezcla pulsional, para finalmente pasar en el último capítulo del texto a despejar la pregunta con una respuesta inquietante: 
el superyó, como representante del ello, toma la fuerza de la pulsión de muerte, abogando en su nombre en el esfuerzo de satisfacción, en particular en una relación perversa -sado-masoquista- del superyó con el yo, tal como formula en "El problema económico del masoquismo", a pocos meses de publicar "El yo y el ello".

La necesidad de castigo es una de las consecuencias de la voz áfona del superyó en las neurosis. Se convierte en una pasión que se impone en la vida de un sujeto y fuerza la repetición de comportamientos que ponen en escena ya sea la necesidad de ser castigados por el Otro o la necesidad de castigar al Otro. Notemos que necesidad no es sinónimo de deseo inconsciente. Da a entender más bien el empuje, drang, el apremio de la pulsión.

En relación con la necesidad de castigo, elabora Freud la categoría conceptual y diagnóstica del masoquismo, no ya como posición de satisfacción en la relación sexual con un partenaire, sino que se refiere en 1924 a la posición inconsciente y de satisfacción pulsional que puede adoptar el yo en una relación perversa con la instancia del superyó, quien adoptaría en tal caso, una satisfacción sádica.

Dos de las formas en que se presenta este tipo de masoquismo, el masoquismo femenino y el masoquismo moral, dan una clara muestra de cómo piensa Freud la vida humana a esa altura de sus elaboraciones: si bien la posición masoquista -femenina o moral- tienen una fuerte alimentación del infantilismo inconsciente del sujeto en relación con el Otro, efecto del mantenimiento del vínculo erótico homosexual con el padre edípico, Freud no reduce la importancia de considerar la satisfacción que el masoquismo femenino o moral le permite a la pulsión de muerte en cada ocasión, más allá del principio del placer.

Ya lo había presentado en ocasión de considerar la función que cumplen los sueños en las neurosis traumáticas, cuando se refirió a las "enigmáticas tendencias masoquistas del yo" (Freud, 1920, p. 14).

\section{LA CLÍNICA DEL SÍNTOMA Y EL DESEO DEL ANALISTA}

Dos dimensiones que Freud procuró diferenciar aunque siempre articuladas, inconsciente y pulsión, especialmente desde "Tres ensayos para una teoría sexual", para una mejor lectura de los hechos clínicos. El inconsciente interpreta y responde al enigma del sexo y del deseo, por la vía del falo/castración. La pulsión, en cambio, se satisface. Allí, como sostiene Lacan, el sujeto siempre es feliz, tanto -o más- cuando sufre, tal como Freud lo relevara en "El problema económico del masoquismo".

La interpretación concierne a lo que incide para transformar a un sujeto. Entonces, será preciso, en primer lugar, tener en cuenta qué es lo que lo constituye y determina, para pensar los medios y los modos de esa modificación.

Para concluir, diremos que:

a) en la ciencia, la significación y la verdad quedan reducidas por la materialidad. Y si la ciencia cura, lo hace por la molécula, por los genes, por los elementos invisibles e insignificantes. Forcluye al sujeto, que no interesa ni cuenta en el asunto.

b)la psicoterapia, en cambio, hace uso del sentido -común-. Y ahí resulta un engaño por la promoción de sentidos coagulados, previamente pret-a-porter para todo el mundo, mediante el poder 
de la sugestión. No toca lo real en juego, porque lo desconoce o lo evita adrede. Da sentido, rápidamente, a la vida y a los problemas de la vida, degradando la densidad de la existencia humana cuando los nombra como trastornos.

c) el psicoanálisis -que inventó Sigmund Freud y prosiguió Jacques Lacan- se interesa por la verdad inconsciente, por la significación del síntoma, considerando que la repetición del síntoma es, al mismo tiempo, un modo de satisfacción, por lo que la responsabilidad ética del analizante en cuanto a sus síntomas, implica no sólo la perspectiva de la verdad inconsciente sino también el modo de satisfacción en el malestar, que se repite tenazmente, fijado a infantilismos anacrónicos. La orientación por la causa y por la satisfacción pulsional reducen el exceso de sentido o el sinsentido.

Cuando la experiencia de un análisis es sostenida por el trabajo de transferencia suficientemente, puede avanzar hacia la extracción de los últimos elementos de la fijación, los que dan cuenta de la represión primaria y de la intensidad pulsional que se manifiestan en la repetición sintomática. Si en función de un trabajo en análisis, orientado por la fijación, por las fixiones singulares, se pudieran extraer, cernir, aquellas marcas y huellas que conciernen íntimamente a las fijaciones singulares de cada sujeto, se podría comprender y, quizás, confirmar la fuerte expresión de Freud, en "Análisis terminable e interminable" cuando se refiere a la operación del análisis como "la rectificación, con posterioridad, del proceso represivo originario, la cual pone término al hiperpoder del factor cuantitativo, sería entonces la operación genuina de la terapia analítica" (Freud, 1937, p. 230).

\section{REFERENCIAS BIBLIOGRÁFICAS}

Freud, Sigmund (1892). "Fragmentos de la correspondencia con Fliess", en Obras completas (Vol. 1), Buenos Aires, Argentina, Amorrortu.

(1893/1895). "Estudios sobre la histeria", en Obras completas (Vol. 3), Buenos Aires, Argentina, Amorrortu.

(1896). "Nuevas observa-ciones sobre las neuropsicosis de defensa", en Obras completas (Vol. 3), Buenos Aires, Argentina, Amorrortu.

(1900). "La interpretación de los sueños”, en Obras completas (Vol. 4 y 5), Buenos Aires, Argentina, Amorrortu. (1905). "Tres ensayos de una teoría sexual”, en Obras completas (Vol. 7), Buenos Aires, Argentina, Amorrortu.

(1914). “Introducción del narcisismo", en Obras completas (Vol. 14), Buenos Aires, Argentina, Amorrortu.

(1920). “Más allá del principio del placer", en Obras completas (Vol. 18), Buenos Aires, Argentina, Amorrortu.

(1923). "El yo y el ello", en Obras completas (Vol. 19), Buenos Aires, Argentina, Amorrortu.

(1924). "El problema económico del masoquismo", en Obras completas (Vol. 19), Buenos Aires, Argentina, Amorrortu.

(1926). "Inhibición, síntoma y angustia”, en Obras completas (Vol. 20), Buenos Aires, Argentina, Amorrortu.

(1937). "Análisis terminable e interminable", en Obras completas (Vol. 23), Buenos Aires, Argentina, Amorrortu. 
Freud, S/ Ferenczi, S. (1908-1911).

"Correspondencia 186 F - Autógrafo 1053 / 8-10, 6/12/1910, Freud a Ferenczi ”, en Correspondencia completa (Vol. I.1), Madrid, España, Editorial Síntesis.

Lacan, Jacques (1962/1963). "EL Seminario 10: La Angustia”. Buenos Aires, Argentina. Paidos. (1964). "El Seminario 11: Los cuatro conceptos fundamentales del Psicoanálisis” Buenos Aires, Argentina, Paidós.

(1973). "El atolondradicho", en Otros escritos. Buenos Aires, Argentina, Paidós.

\section{COMO CITAR ESTE ARTÍCULO:}

Bertholet, R (2019) Freud y la clínica del síntoma en Revista Psicoanálisis en la Universidad $N^{\circ} 3$. Rosario, Argentina. UNR Editora.

Roberto Bertholet

Psicoanalista. Profesor Titular de «Psicoanálisis II» de la Facultad de Psicología de la UNR. Docente responsable de los Seminarios: «La depresión» $\mathrm{y}$ «Las pasiones en la enseñanza de J. Lacan», en la Facultad de Psicología de la UNR. Miembro de la Escuela de la Orientación Lacaniana (EOL). Miembro de la Asociación Mundial de Psicoanálisis (AMP). Miembro de la Escuela de la Orientación Lacaniana, Sección Rosario. Docente del Instituto Oscar Masotta (IOM) 